\title{
Efek Pemanasan Pra-kompaksi dan Sinter terhadap Sifat Kuat Tekan Komposit Al/SiC
}

\author{
Mashuri* dan I. Mufidah \\ Departemen Fisika, Fakultas Sains, Institut Teknologi Sepuluh Nopember (ITS), \\ Kampus ITS Sukolilo, Surabaya 60111
}

\begin{abstract}
Intisari
Penelitian efek pemanasan pra kompaksi pada matrik Al dan sintering terhadap densitas dan kuat tekan komposit $\mathrm{Al} / \mathrm{SiC}$ yang dibuat dengan metode metalurgi serbuk telah dilakukan. Pembuatan komposit $\mathrm{Al} / \mathrm{SiC}$ diawali dengan memanaskan matrik $\mathrm{Al}$ pra-kompaksi pada temperatur 40,60 , dan $80^{\circ} \mathrm{C}$ dalam waktu 1 jam, kompaksi secara mekanik dan disinter pada temperatur 400,500 , dan $600^{\circ} \mathrm{C}$. Guna meningkatkan kehomogenan tekanan saat kompaksi diseluruh bagian komposit digunakan zinc stearate yang tidak reaktif dan mudah menguap. Identifikasi fasa dan morfologi dilakukan dengan menggunakan alat X-rays Difractometry (XRD) dan Scanning Electron Microscope (SEM). Densitas dan porositas diukur dengan metode Archimedes dan kuat tekan diuji dengan alat Torsee Universal Testing Machine. Hasil penelitian menunjukkan pemanasan pra-kompaksi pada matrik Al hingga temperatur $60^{\circ} \mathrm{C}$ dan temperatur sinter hingga $500^{\circ} \mathrm{C}$ dapat meningkatkan nilai densitas dan kuat tekan komposit $\mathrm{Al} / \mathrm{SiC}$ yang dibuat dengan metode metalurgi serbuk. Pemanasan sinter dapat menimbulkan fasa baru $\gamma-\mathrm{Al}_{2} \mathrm{O}_{3}$ pada bidang kontak permukaan $\mathrm{Al}-\mathrm{SiC}$ yang dapat memperkuat ikatan antar muka dan mengurangi porositas sehingga densitas dan kuat tekan meningkat.
\end{abstract}

\begin{abstract}
Research on the effects of pre-compacting heating on Aluminum (Al) matrix and sintering on the density and compressive strength of $\mathrm{Al} / \mathrm{SiC}$ composites made using powder metallurgy method. The synthesized of $\mathrm{Al} / \mathrm{SiC}$ composites was began by heating pre-compacting of $\mathrm{Al}$ matrix at temperatures of 40,60 , and $80^{\circ} \mathrm{C}$ within 1 hour, mechanically compacting and sintering at temperatures of 400,500 , and $600^{\circ} \mathrm{C}$. In order to increase the homogeneity of pressure during compacting throughout in the composites, non-reactive and volatile zinc stearate was used. Phase and morphological identification were carried out using X-rays Diffractometry (XRD) and Scanning Electron Microscope (SEM) devices. The density and porosity were measured by the Archimedes method and the compressive strength was tested by the Torsee Universal Testing Machine. The results showed that pre-compacting in the $\mathrm{Al}$ matrix with the temperature of $60^{\circ} \mathrm{C}$ and sintered temperatures up to $500^{\circ} \mathrm{C}$ can increase the density and the compressive strength of $\mathrm{Al} / \mathrm{SiC}$ composites prepared by powder metallurgy method. Sintering process can give a new phase $\gamma-\mathrm{Al}_{2} \mathrm{O}_{3}$ in the surface area contact of Al-SiC which can strengthen interfacial bonds and reduce porosity so that the density and the compressive strength increase.
\end{abstract}

Keywords: composites; powder metallurgy; pre-compacting; sintering.

*Corresponding author: mash@physics.its.ac.id

http://dx.doi.org/10.12962/j24604682.v15i3.5281

2460-4682 (c)Departemen Fisika, FSains-ITS

\section{PENDAHULUAN}

Seiring berkembangnya ilmu pengetahuan dan teknologi material, bahan komposit matrik metal merupakan salah satu jenis material yang secara ekstensif dilakukan penelitian secara berkelanjutan karena ekselennya sifat fisis yang dimilikinya, sebagai contoh kekuatan tarik tinggi dan ringan pada waktu pemakaian secara bersamaan. Aplikasi material komposit matrik metal yang berkualitas banyak digunakan dan terus meningkat dalam berbagai bidang, khususnya permesinan, aerospace dan transportasi [1]. Material komposit matrik Aluminium (Al) yang diperkuat dengan Silikon Karbida $(\mathrm{SiC})$ merupakan salah satu dari kelompok material yang banyak diaplikasikan dalam bidang manufaktur hingga saat ini. Komposit Al/SiC secara efektif memiliki keuntungan sifat fisis dari perpaduan sifat $\mathrm{Al}$ sebagai matrik dan $\mathrm{SiC}$ sebagai penguat yaitu ringan, anti korosi, tahan gesek, kekuatan tarik dan tekan tinggi, konduksi panas rendah serta keunggulan sifat mekanik dan fisis lainnya [2, 3].

Beberapa metode pembuatan komposit $\mathrm{Al} / \mathrm{SiC}$ yang umum digunakan yaitu melt stirring, infiltrasi-tekanan, squeeze casting, infiltrasi-vakum dan metalurgi serbuk. Metode-metode pembuatan komposit $\mathrm{Al} / \mathrm{SiC}$ tersebut masing-masing memiliki keunggulan dan kelemahan. Metode infiltrasi, casting dan melt stirring diperlukan proses yang tidak sederhana, perlu pemanasan tinggi dan sering terjadi porous yang meng- 
akibatkan sifat fisis dan mekanik menurun serta memerlukan biaya yang mahal [4]. Metode metalurgi serbuk yang mencakup proses pencampuran (blending), molding dan sintering memiliki mekanisme proses yang lebih sederhana dan biaya pembuatan relatif lebih murah [5].

Komposit merupakan kombinasi dua atau lebih material yang berbeda, dengan syarat adanya ikatan permukaan antara kedua material tersebut secara fisis atau ikatan lain dengan menambahkan bahan aditif seperti agen pengganding (coupling agent). Sifat fisis dan mekanik komposit matrik metal ditentukan oleh fraksi volume, bentuk dan ukuran partikel, distribusi dan berhasil tidaknya terbentuk ikatan antar muka (interfacial bonding) [6, 7]. Terbentuknya ikatan antar muka sangat ditentukan oleh ketepatan metode pembuatan, kontrol parameter proses dan ditambah tidaknya bahan lain sebagai aditif semacam agen penggandeng. Efek pemanasan seperti anil dan sinter juga menentukan sifat mekanik dan fisis dari komposit matrik metal, sehingga penting untuk dilakukan penelitian terkait dengan efek pemanasan saat sebelum dan sesudah kompaksi pembentukan komposit matrik metal.

Pada makalah ini disampaikan hasil penelitian efek dari pemanasan pra kompaksi terhadap sifat kuat tekan komposit $\mathrm{Al} / \mathrm{SiC}$ yang dibuat dengan metode metalurgi serbuk. Perilaku kuat tekan komposit Al/SiC dikaji dari segi berhasil tidaknya pembentukan ikatan antar muka yang dikaitkan dengan sifat fisis densitas dan porositas karena pemanasan pra kompaksi. Ikatan antar muka $\mathrm{Al} / \mathrm{SiC}$ diamati dengan alat $X$-ray Difraction (XRD), morfologi distribusi partikel SiC dalam Al diamati dengan Scanning Electron Microscopy (SEM) dan sifat kekuatan tekan diuji dengan alat uji tekan dengan standar ASTM D 695.

\section{METODE EKSPERIMEN}

Bahan yang digunakan dalam penelitian ini adalah serbuk komersil aluminium $\left(\mathrm{Al}, 99 \%, \mathrm{E}=73 \mathrm{GPa}\right.$, titik leleh $638^{\circ} \mathrm{C}$, densitas $2,77 \mathrm{gr} / \mathrm{cm}^{3}$ ), serbuk silikon karbida ( $\mathrm{SiC}, 99 \%, \mathrm{E}=$ $410 \mathrm{GPa}$, titik leleh $2837^{\circ} \mathrm{C}$, densitas $2,9 \mathrm{gr} / \mathrm{cm}^{3}$ ) dan serbuk zinc stearat $\left(\mathrm{Zn}\left(\mathrm{C}_{18} \mathrm{H}_{35} \mathrm{O}_{2}\right)_{2}\right)$. Serbuk zinc stearat berfungsi sebagai bahan pelumas antara campuran serbuk $\mathrm{Al} / \mathrm{SiC}$ dengan dinding cetakan agar gaya tekan pada saat pengujian terdistribusi merata ke segala bagian campuran serbuk baik yang ditengah maupun yang bersinggungan dengan dinding cetakan.

Komposit $\mathrm{Al} / \mathrm{SiC}$ dengan komposisi $\mathrm{Al}: \mathrm{SiC}$ sebesar 80:20\%wt dibuat dengan metode metalurgi serbuk yang meliputi pemanasan pra-kompaksi, kompaksi, pra-sinter, sinter dan selanjutnya dilakukan pengujian kuat tekan. Serbuk Al sebagai matrik dan SiC sebagai pengisi ditimbang sesuai komposisi. Sebelum proses pencampuran serbuk Al sebagai matrik dipanaskan pada temperatur 40,60 , dan $80^{\circ} \mathrm{C}$ masingmasing dalam waktu 1 jam dengan tujuan untuk memudahkan proses pencampuran dan kompaksi. Serbuk Al yang telah dipanaskan dan $\mathrm{SiC}$ kemudian dicampur secara mekanik pada temperatur kamar (dry mixing) sampai homogen menggunakan alat High-Speed Planetary Miller (MTI-SFM1) dalam waktu 5 jam dengan kecepatan putar 100 rpm. Serbuk yang telah tercampur dimasukkan ke dalam cetakan berbentuk silinder yang sebelumnya sudah diolesi dengan zinc stearat untuk mempermudah proses kompaksi. Proses kompaksi dilakukan dengan penekanan sebesar $300 \mathrm{MPa}$ dengan waktu tahan selama 10 menit. Setelah didapatkan sampel sesuai dengan bentuk cetakan yaitu silinder dilakukan proses pra sinter pada temperatur $200^{\circ} \mathrm{C}$ selama 1 jam guna menghilangkan tegangan sisa akibat kompaksi. Selanjutnya dilakukan proses sintering pada temperatur 400,500 , dan $600^{\circ} \mathrm{C}$ dalam waktu 2 jam.

Densitas komposit $\mathrm{Al} / \mathrm{SiC}$ diukur dengan metode Archimedes, terbentuknya fasa baru diamati dengan XRD merk PanAnalytical Type Expert Pro dan morfologi distribusi SiC dalam Al diamati dengan SEM merk FEI type Inspect-S50, kekuatan tekan diuji dengan alat uji tekan Torsee Universal Testing Machine dengan mengacu ASTM D 695.

\section{HASIL DAN PEMBAHASAN}

\section{Efek pemanasan pra-kompaksi dan sinter terhadap densitas}

Pembuatan komposit $\mathrm{Al} / \mathrm{SiC}$ dengan metode metalurgi serbuk meliputi pencampuran, pemadatan serbuk dengan tekanan (kompaksi) dan pemanasan. Kompaksi dilakukan untuk membentuk ikatan mekanik antar partikel $\mathrm{Al}$ dan SiC akibat gaya luar sehingga terbentuk padatan dengan densitas tinggi. Kompaksi dalam pembentukan komposit secara metalurgi serbuk dapat dilakukan pada temperatur kamar disebut kompaksi dingin (cold compressing) dan kompaksi yang dilakukan di atas temperatur kamar (hot compressing). Pada penelitian ini komposit $\mathrm{Al} / \mathrm{SiC}$ dibuat secara kompaksi dingin dengan memberi pemanasan 40,60 , dan $80^{\circ} \mathrm{C}$ masing-masing selama 1 jam pada serbuk $\mathrm{Al}$ dan $\mathrm{SiC}$ terlebih dahulu. Pemanasan pra kompaksi dilakukan guna meningkatkan kemudahan terbentuknya ikatan antar muka secara mekanik akibat penekanan.

Kemudahan terbentuknya ikatan antar muka serbuk $\mathrm{Al}$ sebagai matrik dan $\mathrm{SiC}$ menentukan tingginya densitas komposit. Densitas komposit bergantung pada ukuran partikel pengisi dan tingkat homogenitas kerapatan dalam komposit [1]. Dalam penelitian ini untuk meningkatkan homogenitas kerapatan diupayakan dengan memberikan lubricant/pelumas (zinc stearate) yang dioleskan pada dinding cetakan (diewall compressing) untuk mengurangi gesekan antar partikel dan dinding cetakan. Pelumas yang digunakan adalah zinc stearate tidak reaktif secara kimiawi terhadap campuran serbuk $\mathrm{Al} / \mathrm{SiC}$ dan memiliki titik leleh rendah sehingga pada awal proses sintering pelumas dapat menguap [2].

Tahap akhir pembentukan komposit dalam metalurgi serbuk adalah pemanasan yang disebut sintering. Sintering merupakan suatu proses pengikatan partikel melalui proses pemanasan pada temperatur dibawah titik leleh dari material komposit yang dilakukan sesudah proses penekanan. Sebelum proses sinter, selalu diawali dengan proses presinter dengan tujuan untuk mengurangi residual stress akibat proses kompaksi dan mengeluarkan gas dari atmosfer atau pelumas padat yang terjebak dalam porositas bahan komposit serta menghindari perubahan temperatur yang terlalu cepat pada saat proses 


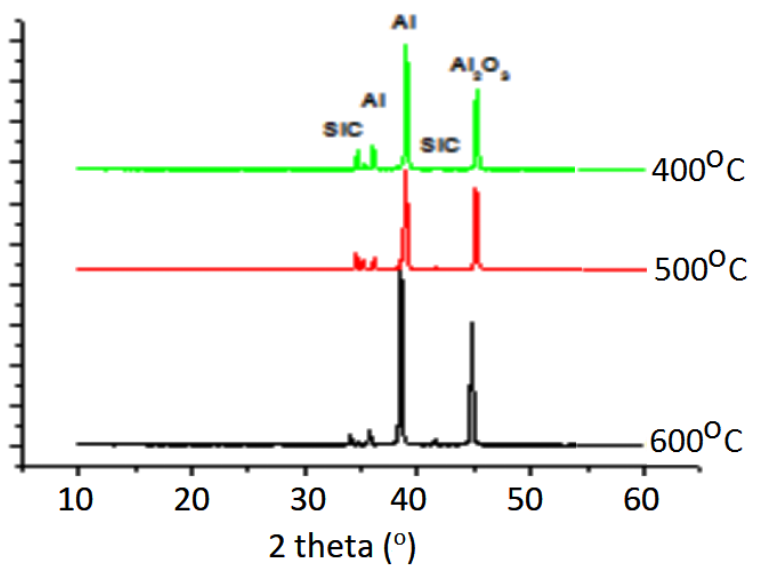

Gambar 1: Difraktogram XRD komposit $\mathrm{Al} / \mathrm{SiC}$ pemanasan pra-kompaksi $40^{\circ} \mathrm{C}$ tersinter 400,500 dan $600^{\circ} \mathrm{C}$.

TABEL I: Fasa terbentuk dalam komposit $\mathrm{Al} / \mathrm{SiC}$ pemanasan pra-kompaksi $40 \mathrm{oC}$ tersinter $400^{\circ} \mathrm{C}$.

\begin{tabular}{ccc}
\hline \hline Sudut $2 \theta\left(^{\circ}\right)$ & $\mathrm{d}(\AA)$ & Fasa \\
\hline & & \\
34,04 & 2,6317 & $\mathrm{SiC}$ \\
35,97 & 2,4950 & $\mathrm{Al}$ \\
38,59 & 2.3313 & $\mathrm{Al}$ \\
41,61 & 2,1689 & $\mathrm{SiC}$ \\
45,78 & 1,9803 & $\gamma-\mathrm{Al}_{2} \mathrm{O}_{3}$ \\
\hline \hline
\end{tabular}

sinter (shock thermal). Pemanasan pada sinter dari komposit $\mathrm{Al} / \mathrm{SiC}$ dengan pemanasan pra kompaksi menyebabkan terbentuknya fasa baru pada permukaan kontak seperti yang ditunjukkan hasil pengujian menggunakan alat XRD pada Gambar 1.

Fasa-fasa yang terbentuk dalam komposit $\mathrm{Al} / \mathrm{SiC}$ pasca sinter yang mengalami pemanasan pra-kompaksi $40^{\circ} \mathrm{C}$ dan rerata ukuran kristal $(d)$ dihitung menggunakan persamaan Bragg: $n \lambda=2 d \sin \theta$ dengan $\lambda$ adalah panjang gelombang, $\mathrm{d}$ merupakan jarak kisi kristal dan $\theta$ adalah sudut difraksi. Hasil analisis menggunakan software Match, untuk ketiga sampel uji yaitu pada temperatur sinter 400,500 , dan $600^{\circ} \mathrm{C}$ dengan suhu pemanasan matrik prakompaksi $40^{\circ} \mathrm{C}$ ternyata mempunyai pola difraksi yang hampir sama. Fasa $\mathrm{Al}$ dan $\mathrm{SiC}$ menunjukkan fasa matrik dan pengisi dalam struktur komposit dan muncul fasa baru yaitu fasa oksida logam $\gamma-\mathrm{Al}_{2} \mathrm{O}_{3}$ (aluminium oxide) pada sudut $2 \theta=45,78^{\circ}$. Terbentuknya formasi $\gamma-\mathrm{Al}_{2} \mathrm{O}_{3}$ pada permukaan $\mathrm{Al}$ dalam lingkungan atmosfer mengikuti persamaan $2 \mathrm{Al}+\frac{3}{2} \quad \mathrm{O}_{2} \longrightarrow \mathrm{Al}_{2} \mathrm{O}_{3}$. Munculnya fasa $\gamma-\mathrm{Al}_{2} \mathrm{O}_{3}$ ini menunjukkan adanya oksidasi yang terjadi saat proses sinter di mana oksigen berinteraksi dengan logam Al. Terbentuknya fasa aluminium oksida dan pemanasan sinter akan menentukan sifat kuat tekan dan densitas komposit $\mathrm{Al} / \mathrm{SiC}$ yang dibuat secara metalurgi serbuk. Sinter pada komposit pasca kompaksi menyebabkan terjadinya ikatan muka antar partikel serbuk, pertumbuhan leher (necking growth), penutupan saluran pori, pembulatan pori dan tahap penyusutan (shrinkage). Gaya adhesi-kohesi antar par-

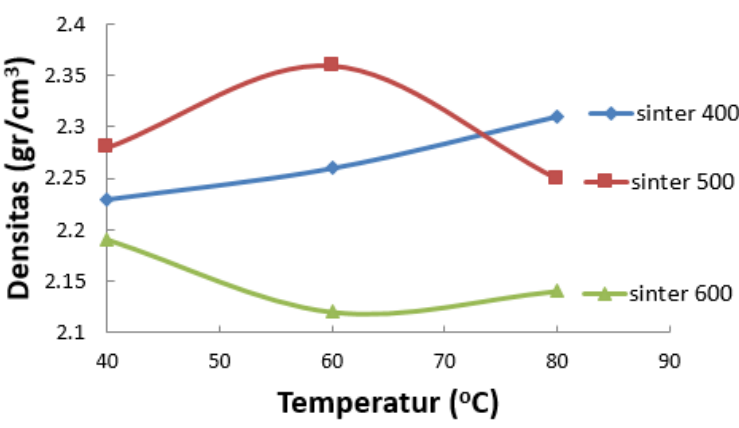

(a)

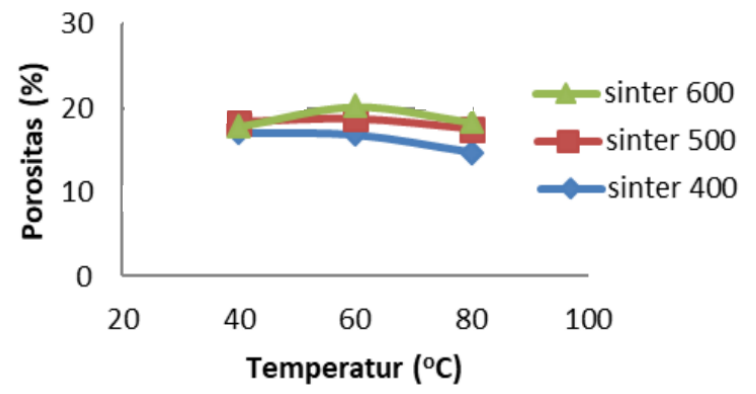

(b)

Gambar 2: Efek pemanasan pra-kompaksi terhadap (a) densitas, dan (b) porositas komposit $\mathrm{Al} / \mathrm{SiC}$ untuk pemanasan pra-kompaksi dari temperatur 40,60 , dan $80^{\circ} \mathrm{C}$.

tikel serbuk merupakan fenomena interaksi awal ikatan antar permukaan partikel setelah proses kompaksi. Fenomena fisis tersebut disebabkan oleh aspek gaya Van der Walls, elektrostatis dan interlocking antar permukaan, hal ini dimungkinkan dapat diperbaiki dengan memberi pemanasan pra kompaksi yang akan menentukan nilai green density.

Densitas dan porositas komposit $\mathrm{Al} / \mathrm{SiC}$ yang telah mengalami pemanasan pra-kompaksi dan sinter dihitung dengan persamaan:

$$
\begin{aligned}
\rho & =\frac{m}{V} \\
\text { dan } & \\
\phi & =\frac{m_{b}-m_{k}}{m_{k}} \times 100 \%
\end{aligned}
$$

dengan $\rho$ : densitas $\left(\mathrm{gr} / \mathrm{cm}^{3}\right), \mathrm{V}$ : volume $\left(\mathrm{cm}^{3}\right), \mathrm{m}$ : massa (gr), $\phi$ : porositas $(\%), \mathrm{m}_{k}$ : massa sampel kering (gram), $\mathrm{m}_{b}$ : massa sampel pasca direndam dalam air (gram). Hasil penghitungan densitas dan porositas ditunjukkan Gambar 2.

Pemanasan prakompaksi matrik $\mathrm{Al}$ dari 40,60 , dan $80^{\circ} \mathrm{C}$, mempermudah terjadinya ikatan kontak permukaan antar partikel baik $\mathrm{Al}$ dengan $\mathrm{Al}$ atau $\mathrm{Al}$ dengan $\mathrm{SiC}$ sebagai pengisi. Hal ini seiring mudahnya dilakukan kompaksi yang menyebabkan jarak antar partikel menjadi semakin semakin kecil sehingga densitas komposit menjadi besar seperti yang ditunjukkan pada Gambar 2(a) pada sintering 400 dan $500^{\circ} \mathrm{C}$ nilai densitas meningkat untuk pemanasan pra kompaksi hingga $60^{\circ} \mathrm{C}$. Menurunnya jarak antar partikel disebabkan 


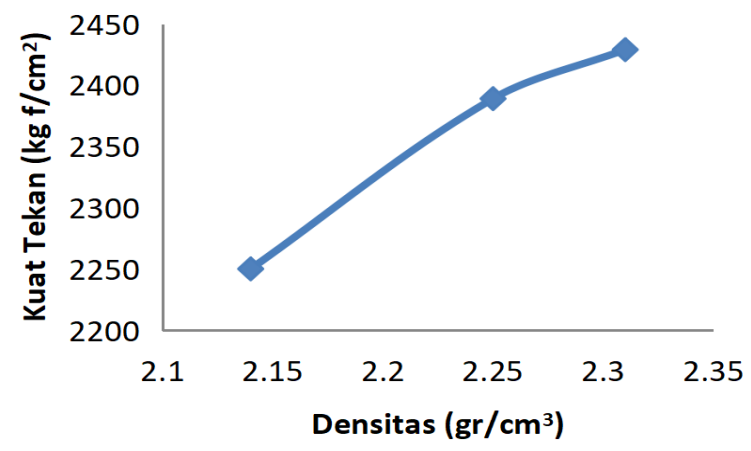

(a)

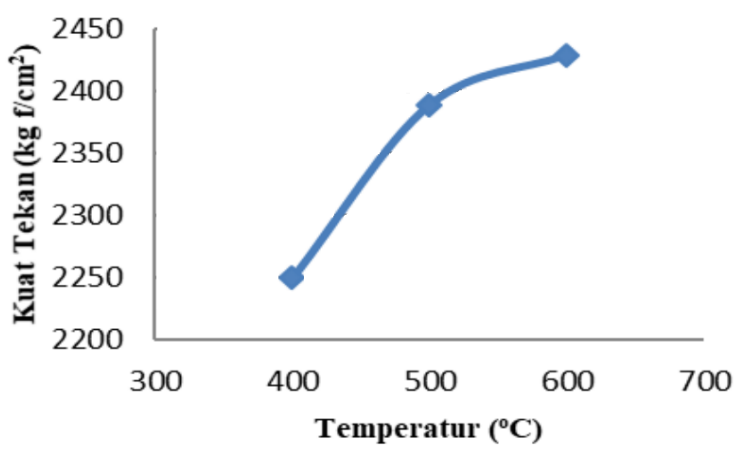

(b)

Gambar 3: Kuat tekan komposit $\mathrm{Al} / \mathrm{SiC}$ (a). pemanasan pra kompaksi 40,60 dan $80^{\circ} \mathrm{C}$ yang disinter $400^{\circ} \mathrm{C}$, (b). pemanasan pra kompaksi $40^{\circ} \mathrm{C}$ yang disintesis 400,500 dan $600^{\circ} \mathrm{C}$.

oleh elastisitas atom-atom dalam kisi sehingga mudah dilakukan pemampatan saat kompaksi, pemanasan sinter hingga $500^{\circ} \mathrm{C}$ dapat meningkatkan ikatan antar muka dan timbul fasa baru $\gamma-\mathrm{Al}_{2} \mathrm{O}_{3}$ sehingga menurunkan densitas crack saturasi Al sebagai matrik [5]. Pada sinter $600^{\circ} \mathrm{C}$ terjadi penurunan nilai densitas hingga pemanasan pra-kompaksi $60^{\circ} \mathrm{C}$ namun terjadi peningkatan densitas pada pemanasan pra-kompaksi $80^{\circ} \mathrm{C}$. Penurunan densitas ini terjadi disebabkan oleh terbentuknya pori sebagai akibat terputusnya ikatan antar muka karena temperatur tinggi dengan intensitas yang lebih banyak dan elastisitas atom-atom dalam kisi sudah menurun sehingga peregangan meningkat menuju plastisitas dari kesetimbangan kisi dan kemungkinan terjadinya cracking sehingga memperbesar volume. Peningkatan densitas pada pemanasan prakompaksi $80^{\circ} \mathrm{C}$ dimungkinkan karena terbentuknya fasa $\gamma$ $\mathrm{Al}_{2} \mathrm{O}_{3}$ pada ikatan antar muka baru Al-SiC yang mereduksi cracking sehingga dapat memperkecil volume.

Densitas suatu material dipengaruhi oleh porositas. Semakin besar temperatur pemanasan pra-kompaksi semakin menurunkan nilai porositas. Penurunan porositas sebagai akibat dari semakin mudahnya partikel matrik-pengisi untuk dilakukan pemadatan melalui kompaksi. Semakin tinggi temperatur pemanasan matrik maka semakin mudah terbentuk ikatan antar partikel semakin kuat sehingga jarak partikel menjadi semakin rapat atau semakin kecil yang menyebabkan pori-pori menurun. Hasil pengujian porositas bahan komposit $\mathrm{Al} / \mathrm{SiC}$ yang mengalami pemanasan pra-kompaksi $40^{\circ} \mathrm{C}$ hingga $80^{\circ} \mathrm{C}$ menunjukkan perilaku penurunan porositas dengan nilai porositas terendah pada temperatur pemanasan prakompaksi matrik $80^{\circ} \mathrm{C}$ pada temperatur sinter $400^{\circ} \mathrm{C}$ sebesar $14,74 \%$. Namun data masih menunjukkan ketidak konsistenan terhadap nilai densitas secara teoritis di karenakan masih dimungkinkan ketidak seragaman dalam distribusi pengisi karena ketidak sempurnaan dalam proses pencampuran padat. Tingkat keporousan komposit juga dipengaruhi oleh distribusi serbuk. Pada komposit Al-SiC porositas terjadi pada daerah antar muka matrik dan penguat. Jika distribusi serbuk SiC kurang merata terhadap matriknya, maka belum terjadi kontak permukaan yang baik antar kedua serbuk sehingga material tersebut semakin porous.

\section{Pengaruh pemanasan sinter terhadap kuat tekan}

Kuat tekan suatu bahan adalah kemampuan bahan dalam menahan beban atau gaya mekanik dari luar sampai terjadinya kerusakan (failure). Kuat tekan suatu bahan dihitung dengan persamaan:

$$
P=\frac{F}{A}
$$

dengan P: kuat tekan (kgf/cm²), F: beban maksimum (kgf), A: luas penampang sampel uji $=\pi \mathrm{d}^{2} / 4\left(\mathrm{~cm}^{2}\right)$. Nilai kuat tekan dipengaruhi oleh nilai densitas, semakin tinggi nilai densitas dari suatu bahan maka semakin tinggi nilai kuat tekannya. Bahan komposit $\mathrm{Al} / \mathrm{SiC}$ yang dibuat secara metalurgi serbuk yang meliputi tahap pencampuran, pemadatan dan pemanasan (pra-kompaksi dan sinter) maka kuat tekan sangat ditentukan oleh densitas. Densitas komposit ditentukan oleh keberhasilan ketiga tahapan tersebut. Densitas komposit yang tinggi maka komposit tersebut memiliki kuat tekan yang tinggi pula, artinya dibutuhkan energi mekanik yang besar untuk menghancurkan komposit tersebut. Kuat tekan komposit $\mathrm{Al} / \mathrm{SiC}$ yang dibuat dengan metalurgi serbuk pada pemanasan pra-kompaksi dan sinter ditunjukkan Gambar 3.

Nilai kuat tekan tertinggi diperoleh dengan nilai 2429 $\mathrm{kgf} / \mathrm{cm}^{2}$ atau setara dengan $243 \mathrm{MPa}$ pada temperatur $600^{\circ} \mathrm{C}$. Secara teoritik nilai kuat tekan dari komposit $\mathrm{Al} / \mathrm{SiC}$ berkisar antara 300-450 MPa. Nilai ini masih jauh berbeda dengan kuat tekan yang diperoleh secara eksperimen. Hal ini kemungkinan juga disebabkan oleh distribusi dari partikel serbuk $\mathrm{Al}$ dan $\mathrm{SiC}$ yang kurang merata sehingga ikatan antara matrik $\mathrm{Al}$ dan penguat $\mathrm{SiC}$ kurang maksimal sehingga pada penekanan dengan gaya $243 \mathrm{MPa}$ sampel uji sudah hancur (retak).

Gambar 4 menunjukkan morfologi permukaan komposit hasil pengamatan menggunakan SEM dengan perbesaran 3000X. Pada dasarnya kehomogenan distribusi Al/SiC akan berpengaruh pada kualitas sifat kuat tekan. Dalam tahap awal proses sintering, atom-atom akan bergerak untuk memperbanyak jumlah kontak antar partikel. Kondisi ini kemudian 


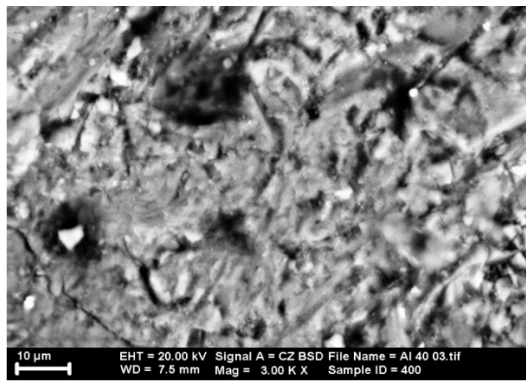

(a)

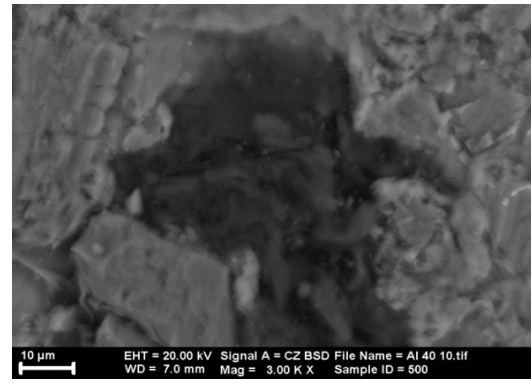

(b)

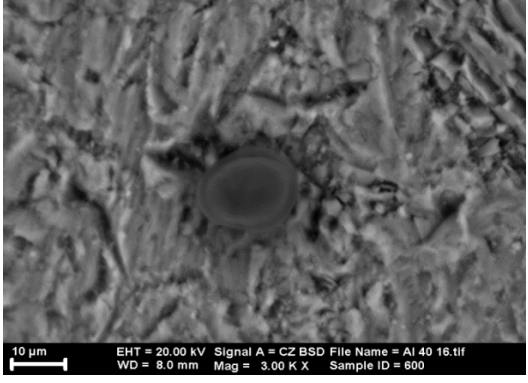

(c)

Gambar 4: Foto SEM komposit $\mathrm{Al} / \mathrm{SiC}$ pemanasan prakompaksi $40^{\circ} \mathrm{C}$ tersinter (a). $400^{\circ} \mathrm{C}$ (b). $500^{\circ} \mathrm{C},(\mathrm{c}) .600^{\circ} \mathrm{C}$.

terus mengalami perbaikan di tahap-tahap berikutnya dengan terbentuknya ikatan antar partikel $\mathrm{Al}$ dan SiC yang terusmenerus mengeliminasi porositas antar butir selama holding time. Semakin homogen distribusi partikel, maka semakin besar pula porositas yang tereliminasi, yang berimbas pada kepadatan dari komposit $[6,8]$. Hasil pengamatan SEM pada Gambar 4 untuk masing-masing temperatur menunjukkan masih terdapat belum sempurnanya distribusi $\mathrm{SiC}$ dalam $\mathrm{Al}$ dan ikatan antar muka sehingga dapat mengurangi sifat fisis dan kuat tekan dari komposit. Ketidak sempurnaan pembentukan ikatan antar muka partikel Al dan $\mathrm{SiC}$ menyebabkan mudah terputusnya ikatan antar muka (cracking) tersebut membentuk pori ketika mendapatkan panas sinter yang tinggi [9]. Hal ini terlihat pada sinter 500 dan $600^{\circ} \mathrm{C}$ yang ditunjukkan Gambar 4(b) dan 4(c) pori terlihat menjadi lebih besar sehingga berpengaruh pada densitas dan kuat tekan komposit Al/SiC. Pada penelitian ini didapat densitas tertinggi 2,36 $\mathrm{gr} / \mathrm{cm}^{3}$ dan kuat tekan $243 \mathrm{MPa}$ yang masih berbeda dengan nilai densitas dan kuat teoritis antara 2,6-3,1 $\mathrm{gr} / \mathrm{cm}^{3}$ dan 300-400 MPa. Pemanasan pra kompaksi pada temperatur $60^{\circ} \mathrm{C}$ dan sintering pada temperatur $500^{\circ} \mathrm{C}$ kombinasi pemanasan yang terbaik untuk mendapatkan kuat tekan terbaik dari komposit $\mathrm{Al} / \mathrm{SiC}$ yang dibuat secara metalurgi serbuk.

\section{SIMPULAN}

Pemanasan pra-kompaksi pada matrik Al hingga temperatur $60^{\circ} \mathrm{C}$ dan temperatur sinter hingga $500^{\circ} \mathrm{C}$ dapat meningkatkan nilai densitas dan kuat tekan komposit $\mathrm{Al} / \mathrm{SiC}$ yang dibuat dengan metode metalurgi serbuk. Peningkatan densitas dan kuat tekan komposit $\mathrm{Al} / \mathrm{SiC}$ dimungkinkan karena terbentuknya fasa $\gamma-\mathrm{Al}_{2} \mathrm{O}_{3}$ pada bidang kontak permukaan $\mathrm{Al}-\mathrm{SiC}$ akibat pemanasan sinter. Fasa $\gamma-\mathrm{Al}_{2} \mathrm{O}_{3}$ dapat memperkuat ikatan antar muka dan mereduksi porositas sehingga densitas dan kuat tekan meningkat.
[1] T. Ve, Y. Xu, J. Ren, "Effects of SiC particle size on mechanical properties of $\mathrm{SiC}$ particle reinforced aluminum metal matrix composite', Materials Science \& Engineering A, vol. 753, pp. 146-155, 2019.

[2] H. Izadi, et al., "Friction Stir Processing of $\mathrm{Al} / \mathrm{SiC}$ Composite Fabricated by Powder Metallurgy", Journal of Material Processing Technology, vol. 213, pp. 1900-1907, 2013

[3] A.K. Kumar Bodukuri, K. Eswaraiah, K. Rajendar, V. Sampath, "Fabrication of Al-SiC-B4C metal matrix composite by powder metallurgy technique and evaluating mechanical properties", Perspectives in Science, vol. 8, pp. 428-431, 2016.

[4] M. Zainuri, E.S. Siradj, D. Priadi, A. Zulfia, dan D. Darminto, "Pengaruh Pelapisan Permukaan Partikel SiC dengan Oksida Metal terhadap Modulus Elastisitas Komposit Al/SiC'. Jurnal MAKARA, SAINS, vol. 12, no. 2, hlm. 126-133, 2008.

[5] X. Han, X. Gao, Y. Song, "Effect of heat treatment on the microstructure and mechanical behavior of $\mathrm{SiC} / \mathrm{SiC}$ minicomposites", Materials Science \& Engineering A, vol. 753, pp.
146-155, 2019.

[6] D. Mandal, S. Viswanathan, "Effect of heat treatment on microstructure and interface of $\mathrm{SiC}$ particle reinforced $2124 \mathrm{Al}$ matrix composite", Materials Characterization, vol. 85, pp. 73-81, 2013.

[7] J.M. Zhan, et al., "Tensile deformation of nanocrystalline Almatrix composites: Effects of the $\mathrm{SiC}$ particle and graphene", Computational Materials Science, vol. 156, pp. 187-194, 2019.

[8] F. Teng, et al., "Microstucture and properties of Al-50\% SiC composites for electronic packaging applications", Transactions of Nonferrous Metals Society of China, vol. 26, pp. 2647-2652, 2016.

[9] B.L. Madej, D. Garbiec, M. Madej, "Effect of sintering temperature on microstructure and selected properties of spark plasma sintered Al-SiC composites", Vacuum, vol. 164, pp 250-255, 2019. 